\title{
O GEMÜT E AS DOENÇAS DA CABEÇA: O LADO OBSCURO DA ANTROPOLOGIA $^{1}$
}

\author{
Jorge Conceição (PUC-PR)² \\ anedotismo@yahoo.com.br
}

Resumo: Este artigo objetiva reconstruir a ideia de uma natureza humana em Kant através do funcionamento das faculdades cognitivas. Para realizar tal tarefa, problematizaremos a sensibilidade do ponto de vista das doenças da cabeça, as quais nos permitem compreender o funcionamento da natureza humana a partir das faculdades cognitivas. Investigar a natureza humana, através das faculdades cognitivas, significa que a interrogaremos sobre a perspectiva de quais são as condições materiais que tornam possíveis a exequibilidade de proposições sintéticas a priori. As vantagens desta abordagem são as seguintes: i) permite entender como o substrato material altera as operações judicativas e como estas o delimitam; ii) autoriza classificar diferentes níveis de operações da sensibilidade.

Palavras-chave: doenças da cabeça; ânimo; receptividade; sensitividade e suscetibilidade.

\section{INTRODUÇÃO}

Para caracterizar a natureza humana como executora das operações que tornam possíveis os juízos, alinharemos duas obras kantianas que focam o tema das doenças da cabeça, que são: o Ensaio sobre as doenças da cabeça ${ }^{3}$ de 1764 e a An-

\footnotetext{
${ }^{1}$ Recebido: 06-06-2014/Aprovado: 16-08-2014/Publicado on-line: 08-09-2014.

${ }^{2}$ Jorge Conceição é Doutorando no Departamento de Filosofia da Pontifícia Universidade Católica do Paraná, Curitiba, PR, Brasil.

${ }^{3}$ As obras de Kant serão citadas pelas siglas estabelecidas internacionalmente pela direção da Revista Kant-Studien e adotadas pela Kant-Gesellschaft, a Sociedade Kant Brasileira, a Revista Studia Kantiana e a revista Kant e-prints. Ver http://www.degruyter.com/files/ down/instructions/ksins_e.pdf
} 
tropologia de um ponto de vista pragmático de 1798 . Na primeira obra, Kant nomeou as deficiências da faculdade de conhecer (Erkenntnisvermögens) de doenças da cabeça, cujos transtornos produzem efeitos judicativos. Ao classificar os problemas judicativos como doenças da cabeça, Kant aventou a hipótese de que os erros na execução dos juízos resultavam de alterações somáticas do corpo, que modificavam o modo de funcionamento da faculdade de conhecer ${ }^{4}$. Assim, o modo de funcionamento das faculdades cognitivas não eram a causa dos juízos enfermos, mas tais sentenças eram consequências de alterações físicas ${ }^{5}$ no executor de opera-

\footnotetext{
${ }^{4}$ Teruel (Cf. 2013) defendeu uma releitura contemporânea do Ensaio sobre as doenças da cabeça, ele interpretou a relação entre as doenças da cabeça e as faculdades cognitivas sob o ponto de vista da base neurofisiológica das atividades mentais (TERUEL 2013, p.38). Ele propôs uma "influência física" (physischen Einflusses) sobre os estados mentais, que indicaria um funcionamento mecânico do corpo humano. Ele sustentou a sua argumentação em dois pontos: no primeiro, ele tratou da reconstrução histórica dos semanários Der Arzt, especialmente os números 150, 151 e 152; no segundo, ele alinhou o funcionamento da natureza humana a um processador computacional, assim dissolvendo qualquer pretensão de dualidade entre corpo e mente, ou seja, ele propôs interpretar o termo Gemüt através da noção contemporânea de mente estendida. Por fim, Teruel considerou a mente (Gemüt) como uma estrutura judicativa que pode ser aplicada a vários tipos de arquitetura física, que pode ser tanto o cérebro humano quanto a máquina de Turing, desde que eles executem as sequências de processamentos de dados determinadas pelas operações judicativas. Conforme o comentador, "neste contexto teórico os estados mentais são determinados assim que a rede funcional se relaciona - independente do seu material físico - como processos de informações puras. O material pode ser substituído por qualquer outro corpo (orgânico ou artificial), desde que o sistema substituto reproduza as operações judicativas independente de como a rede funcione. Os processos de tal rede se realizam em um mecanismo de entrada e saída semelhante como na máquina de Turing" (TERUEL 2013, p.39). Todavia, neste artigo reconstruiremos a natureza humana como executora de processos judicativos e, em um artigo futuro intitulado $\mathrm{O}$ Gemüt e as doenças da cabeça: o lado obscuro da antropologia parte 2, debateremos as interpretações da relação entre a natureza humana e as faculdades cognitivas e proporemos interpretá-la como executora de regras.

${ }^{5}$ Frierson defende, em seus trabalhos Kant on mental disorder. Part 1: an overview (2009a) e Kant on mental disorder. Part 2: philosophical implications of Kant's account (2009b), a relação entre os problemas corporais e as faculdades cognitivas, sob a condição de que os estados mentais provocam os estados corporais. De acordo com Frierson, Kant se opôs às explicações fisiológicas que procuravam enfatizar às bases corporais dos estados mentais, mas que ele incluíra em sua antropologia as descrições de como os estados mentais alterariam os estados corporais. Deste modo, as taxonomias das enfermidades do ânimo presentes tanto no Ensaio sobre as doenças da cabeça quanto na Antropologia de um ponto de vista pragmático, ao invés de descrever como os estados corporais alterariam os estados mentais, elas delimitam como os estados mentais provocam os estados corporais. Para Frierson, "a faculdade da cognição está subdividida em uma variedade de Cont.
} 
ções judicativas. Para apresentar a hipótese da causa corpórea das deficiências da faculdade de conhecer, Kant citou o semanário Der Arzt, uma vez que tal revista semanal de divulgação científica lhe permitiu aventar a seguinte hipótese:

[...] quando se atenta um pouco nos exemplos, reconhece-se que sofre primeiro o corpo: que no início quando o germe da doença se desenvolve imperceptivelmente, se sente uma inversão ambígua da mente (Gemüt) que não encerra a suspeita de uma perturbação do ânimo, que se expressa em caprichos amorosos profundos, numa atitude enfatuada e por último num matutar profundo e estéril $(K d K$ $2: 270)^{6}$.

Segundo as indicações de Kant, primeiro sofre o corpo e os juízos desvairados são resultado de enfermidades corpóreas, que provocam uma falsa direção do sentido na

\footnotetext{
diferentes poderes cognitivos - a sensibilidade, a imaginação, faculdade de julgar, o entendimento e a razão - e as desordens cognitivas mentais podem ser distinguidas por qual poder cognitivo é afetado e como" (FRIERSON 2009b. p. 292). Ele propôs que a teoria das doenças da cabeça faz parte da antropologia pragmática, contanto que determine como estados mentais alteram estados corporais, pois Kant se opôs às teorias fisiológicas do séc. XVIII que procuravam determinar as bases corpóreas dos estados mentais. Segundo o comentador, "até certo ponto, Kant seria agradavelmente surpreendido com o desenvolvimento de descrições neurobiológicas do transtorno mental. Embora ele se refira às «indagações sobre a maneira que os órgãos do corpo estão conectados com o pensamento" como "eternamente inútil" (10: 146), ele está disposto e até ansioso para apelar para tratamentos fisiológicos quando eles são confiáveis e disponíveis (ver 7: 213, 220). Quando Kant insiste em que os filósofos, em vez de médicos, devem determinar a sanidade em contextos jurídicos, é por causa do estado embrionário da ciência médica (7: 214). Mesmo quando ele se opõe às abordagens fisiológicas à antropologia, ele refere-se às ambas abordagens que enfatizam as bases corporais de estados mentais e, mais importante, para abordagens que não podem ser colocadas em qualquer utilidade prática. Para Kant, a primeira abordagem implica na última por causa do conhecimento limitado de como manipular o corpo para provocar mudanças no estado mental" (FRIERSON 2009b. p. 307). Em seus artigos supracitados, Frierson investigou a relação entre as faculdades cognitivas e as doenças da cabeça através da perspectiva de como e qual faculdade cognitiva era afetada. Ao contrário dele, procuraremos determinar quais são as características da natureza humana a partir das faculdades cognitivas, uma vez que daremos ênfase à reconstrução da natureza humana a partir da ação do ânimo sobre o corpo e do corpo sobre o ânimo.

${ }^{6}$ Wenn man nur ein wenig auf die Beispiele acht hat, so wird man gewahr: daß zuerst der Körper leide, daß im Anfange, da der Keim der Krankheit sich unvermerkt entwickelt, eine zweideutige Verkehrtheit gespürt wird, die noch keine Vermutung einer Störung des Gemüts giebt, und die sich in wunderlichen Liebesgrillen, oder einem aufgeblasenen Wesen, oder in vergeblichem tiefsinnigem Grüblern äußert.
} 
mente. Para denotar a alteração de um ou mais dos cincos sentidos, Kant utilizou-se do conceito Verkehrtheit, que no caso específico do Ensaio sobre as doenças da cabeça significa a mudança da direção de um ou mais dos cinco sentidos. $\mathrm{Na}$ Antropologia de um ponto de vista pragmático, Kant explicita:

[...] os sentidos da sensação corporal podem ser divididos em sentidos da sensação vital (sensus vagus) e da sensação do órgão (sensus fi$x u s$ ), e porque todos eles só são encontrados onde há nervos, podem ser divididos entre aqueles que afetam o sistema nervoso inteiro e aqueles que só afetam o nervo pertencente a certo membro do corpo (Anth 7:154)?

Nesta citação, Kant destacou o papel do nervo na produção da sensação externa e a dividiu em dois tipos, que são: a produzida por atividade nervosa da sensação vital e a produzida por atividades nervosas da sensação do órgão. A diferença entre esses dois tipos de sensação nervosa é que: na primeira, a sensação percorre e domina todo o corpo humano, como por exemplo, a sensação de calor e de frio; na segunda, a sensação é produzida por um dos sentidos mediante um órgão específico, por exemplo, a imagem do objeto captada pela retina do olho. Em ambas as obras de períodos distintos, Kant apresentou a ideia de que os nervos são responsáveis por produzir sensações. A diferença entre as obras pode ser delimitada pela ampliação do modo causal das doenças da cabeça na Antropologia de um ponto de vista pragmático em comparação com o Ensaio sobre as doenças da cabeça. Nesta obra, as enfermidades mentais eram modificações causadas por modificações nas operações mecânicas

\footnotetext{
${ }^{7}$ Man kann zuerst die Sinne der Körperempfindung in den der Vitalempfindung (sensus vagus) und die der Organempfindung (sensus fixus) und, da sie insgesamt nur da, wo Nerven sind, angetroffen werden, in diejenigen einteilen, welche das ganze System der Nerven, oder nur den zu einem gewissen Gliede des Körpers gehörenden Nerven afficiren.
} 
e químicas do corpo humano, que originavam os problemas judicativos. Na obra de 1798, Antropologia de um ponto de vista pragmático, as doenças da cabeça eram classificadas como um curso arbitrário do pensamento, que possui uma regra própria (subjetiva), contrária à regra objetiva que concorda com as leis da experiência. Diferentemente da primeira, na segunda obra as doenças da cabeça não são somente disfunções corporais, mas também mentais.

$\mathrm{Na}$ última obra, Kant argumentou que a sensibilidade (Sinnlichkeit) na faculdade de conhecer possuía duas partes, que são: o sentido (Sinn) - a faculdade da intuição na presença do objeto e a faculdade da imaginação (Einbildungskraft) - que é a faculdade da intuição sem a presença do objeto. De tal modo:

[...] os sentidos, porém, são divididos por sua vez em sentido externo e interno (sensus internus); o primeiro é aquele em que o corpo humano é afetado pelas coisas corporais, o segundo, é aquele em que o corpo é afetado pela mente, onde se deve notar o último, como mera faculdade de percepção (Anth 7:153).

Ainda de acordo com a obra de 1798, as perturbações mentais que dizem respeito às representações sensíveis são a amência (Unsinnigkeit) e a demência (Wahnsinn) (Cf. Anth 7:202). A primeira trata "da incapacidade de colocar suas representações tão-somente na conexão necessária para a possibilidade da experiência” (Anth 7: 214). Na segunda, "a perturbação mental em que tudo o que narra o louco está realmente conforme as leis formais do pensamento para a possibilidade de uma experiência, mas que em representações criadas pela falsa imaginação poética são consideradas percepções" (Anth 7:215).

Torna-se necessário ainda observar, que o sentido externo é o modo como o corpo é afetado por coisas corpó- 
reas, por isso, não diz respeito à apercepção pura, compreendida como a unidade lógica que acompanha todas as representações, mas sim a união de todas as representações do ânimo no sentido material. Por união de todas as representações do ânimo no sentido material, entendemos o estado fisiológico (estado corporal) do executor de operações judicativas, que por sua vez é o meio físico que torna possível a exequibilidade de proposições válidas ${ }^{8}$. Também é importante observar, que a unidade física do executor de operações judicativas, como chamarei a partir de agora, é a união de todas as representações do ânimo no sentido material, que é diferente da representação do ânimo no sentido psicológico. Todavia, ao delimitar a distinção entre o estado corpóreo e o estado psicológico do executor de operações judicativas implica em duas dificuldades. A primeira refere-se ao sentido interno (innere Sinn) e dá ênfase ao modo como o corpo sofre quando é afetado pelo jogo dos próprios pensamentos por intermédio da faculdade da imaginação. A segunda é derivada analiticamente da primeira, esta dificuldade sugere que muitos dos estados corporais são estados psicológicos, uma vez que sugere que estados mentais são causas de estados corporais. Estas dificuldades são essenciais para compreender a diferença entre

\footnotetext{
${ }^{8} \mathrm{Na}$ Crítica da razão pura, Kant definiu que o problema central dessa obra é: como são possíveis proposições sintéticas a priori? Historicamente essa indagação foi interpretada de diferentes maneiras, por exemplo, Kitcher (Cf. 1990) defendeu que a primeira Crítica é uma psicologia transcendental, na medida em que a teoria dos juízos kantiana engloba elementos psicológicos e antropológicos, que são imprescindiveis para responder a questão fundamental da filosofia crítica. Em linhas gerais, Kitcher defendeu a interpretação da filosofia transcendental kantiana por meio da psicologia cognitivista, que explica as operações executadas pela razão como operações psicológicas. Assim, ela admite a associação dos processos judicativos com os processos fisiológicos, isto significa que estes processos poderiam ser explicados por aqueles e vice-versa. Contudo, neste artigo, queremos apenas enfatizar a relevância do problema da relação entre o substrato material e as operações judicativas, para isso reconstruiremos a noção de natureza humana a partir da ação do ânimo sobre o corpo e como o ânimo afeta o corpo.
} 
o texto Ensaio sobre as doenças da cabeça de 1764 e a obra Antropologia de um ponto de vista pragmático de 1798. Em 1764, Kant não dividiu a sensibilidade em duas partes como encontramos na obra de 1798. Um dos motivos desta distinção entre o sentido interno (o modo como o corpo é afetado pela mente) e o sentido externo (a maneira como o corpo é afetado por coisas corporais) pode ser evidenciado pelo desenvolvimento da faculdade da imaginação na obra de 1798, que considera os elementos da filosofia crítica.

Contudo, por ora, delimitaremos a unidade material ao aspecto da sensação corporal (Organempfindung) e da sensação vital (Vitalempfindung), ou seja, do sentido externo (äußeren Sinn), uma vez que no Ensaio sobre as doenças da cabeça, as enfermidades do ânimo são classificadas como a inversão (Verkehrtheit) das faculdades cognitivas. O Dicionário dos irmãos Grimm, definiu Verkehrtheit como a direção falsa do sentido (falsche Richtung des Sinnes), uma vez que esse termo resulta da substantivação do seguinte advérbio de modo, a saber, verkehrt, que significa do avesso. Ao defendemos que a inversão significa uma direção falsa do sentido, objetivamos asseverar que as doenças da cabeça dizem respeito às alterações corporais que alteram operações judicativas, porque essas modificações corporais transformam a sensação sensível produzida pelo nervo ou por um dos cincos sentidos, que por sua vez altera o processo judicativo ao modificar a intensidade dos dados corporais. Por fim, por ora, definimos que as doenças da cabeça dizem respeito ao sentido externo como resultado da condição material do executor de operações judicativas, essas enfermidades corporais fornecem indícios de que modo a estrutura material do executor funciona e que tipo de problema pode apresentar. Para validar o nosso modo interpretativo da questão 
proposta, dividimos este artigo em três argumentos.

O primeiro tratará de como as sensações externas (corporais) tornam-se sensações internas na medida em que Kant aventou a hipótese de que as doenças da cabeça eram reflexos de problemas corporais em Ensaio sobre as doenças da cabeça. O segundo discorrerá sobre as diferenças entre o Ensaio sobre as doenças da cabeça, publicado em 1764, e a Antropologia de um ponto de vista pragmático. Na obra de 1764, as doenças da cabeça eram a transformação de uma sensação corporal em uma sensação do sentido interno, visto que as doenças da cabeça eram ocasionadas por um distúrbio de um dos órgãos do corpo humano. Em 1798, a relação entre o corpo e o ânimo ocorre de dois modos: primeiro, é igual ao acima apresentado; segundo, o corpo é afetado por representações suscitadas pelo ânimo. O terceiro diferenciará as funções da sensibilidade chamadas por Kant de receptividade (Empfänglichkeit), de sensitividade (Empfindsamkeit) e de suscetibilidade (Empfindelei), que dizem respeito à maneira de como a sensibilidade é afetada pelo ânimo de forma passiva e ativa. Por fim, teremos elencados os elementos materiais do executor de operações judicativas, os quais nos permitirão caracterizar a natureza humana como executora desses procedimentos.

\section{AS DOENÇAS DA CABEÇA: PROBLEMAS SOMÁTICOS}

Em Ensaio sobre as doenças da cabeça, publicado em 1764, Kant apresentou os primeiro elementos da sua teoria da loucura, na medida em que ele se utilizou de conceitos médicos para classificar as disfunções mentais como alterações fisiológicas. Para realizar tal classificação, ele utilizou dois 
critérios: o primeiro é a constatação fisiológicoobservacional, já que as doenças do ânimo são manifestações de um cérebro doente; o segundo é um acréscimo ao primeiro, porque é o resultado da influência de paixões fortes que agravam o estado doentio do ser racional finito. Conforme Kant,

todas as demais manifestações do cérebro doente podem ser entendidas, no meu parecer, quer como graus diferentes dos estados referidos, quer como uma infeliz combinação destes males entre si, ou ainda como resultado do enxerto em paixões fortes, de maneira que as podemos subordinar à classificação anterior (KdK 2:264). ${ }^{9}$.

Tais estados referidos na citação são três, que acometem cada uma das faculdades cognitivas. A primeira graduação das doenças da cabeça é a enfermidade do entendimento, a qual Kant chamou de desarranjo (Verrückung), contanto que ocorra a inversão das sensações externas (corporal) em sensações internas (psicológicas). A segunda graduação das disfunções do ânimo é a mania da faculdade de julgar, que é caracterizada como demência (Wahnsinn), pois há a desordem da experiência empírica. A terceira graduação das deficiências da cabeça é a inversão da razão na elaboração de juízos universais, que recebeu o nome de insânia (Wahnwitz) $^{10}$. Esses três distúrbios de ânimo, no Ensaio sobre as doenças da cabeça, são manifestações de problemas corporais, que por sua vez são a causa dos problemas judicativos.

\footnotetext{
${ }^{9}$ Alle übrige Erscheinungen des kranken Gehirns können, wie mich dünkt, entweder als verschiedene Grade der erwähnten Zufälle, oder als eine unglückliche Vereinbarung dieser Übel unter einander, oder endlich als die Einpfropfung derselben auf mächtige Leidenschaften angesehen und den angeführten Classen untergeordnet werden.

${ }^{10}$ Cf. [...] erstich die Verkehrtheit der Erfahrungsbegriffe in der Verrückung, zweitens die in Unordnung gebrachte Urteilskraft zunächst bei dieser Erfahrung in dem Wahnsinn, drittens die in Ansehung allgemeinerer Urteile verkehrt gewordene Vernunft in dem Wahnwitze (KdK 2:264).
} 
Como já dito, o segundo critério é um acréscimo ao primeiro, sob a condição de que as paixões potencializam o estado doentio do ser racional finito.

\section{Conforme Kant,}

divido estas doenças em dois tipos: o primeiro é a impotência (Ohnmacht), o segundo é a inversão (Verkehrtheit). As primeiras caem sob o título geral de idiotia, as segundas sob o de ânimo perturbado. $\mathrm{O}$ idiota encontra-se numa grande impotência da memória, do entendimento e geralmente também das sensações. Este mal é, na maior parte dos casos, incurável, pois se a supressão do caos do cérebro perturbado já é difícil de suprimir, deve ser quase impossível insuflar uma vida nova nos seus órgãos que deixaram de funcionar. As manifestações desta fraqueza que nunca permitem aos infelizes que dela padecem sair da condição infantil, que são por demais conhecidas pelo que não é necessário alongar-me mais a seu respeito ( $K d K ~ 2$ : $264-265)^{11}$.

Conforme a citação, podemos inferir que a separação das deficiências anímicas proposta por Kant é similar à proposta elaborada por Unzer, que era o editor do semanário Der Arzt. Para Unzer, havia dois tipos de doenças da cabeça: as fraquezas do ânimo e as doenças ânimo. $\mathrm{O}$ primeiro tipo de doenças da cabeça era causado por alterações na força vital que exercia a função controladora dos processos orgânicos. O segundo tipo de doenças da cabeça eram as doenças da bílis escura, pois eram originadas por alterações corpóreas ocasionadas pela combinação da ali-

\footnotetext{
${ }^{11}$ Ich teile diese Krankheiten zwiefach ein, in die der Ohnmacht und in die der Verkehrtheit. Die erstere stehen unter der allgemeinen Benennung der Blödsinnigkeit, die zweite unter dem Namen des gestörten Gemüts. Der Blödsinnige befindet sich in einer großen Ohnmacht des Gedächtnisses, der Vernunft und gemeiniglich auch sogar der sinnlichen Empfindungen. Dieses Übel ist mehrenteils unheilbar, denn wenn es schwer ist die wilde Unordnungen des gestörten Gehirns zu heben, so muss es beinahe unmöglich sein in seine erstorbene Organen ein neues Leben zu gießen. Die Erscheinungen dieser Schwachheit, welche den Unglücklichen niemals aus dem Stande der Kindheit herausgehen lässt, sind zu bekannt, als daß es nötig wäre sich dabei lange aufzuhalten (KdK 2:264-265).
} 
mentação com a predisposição do ânimo do ser racional finito. Parafraseando Unzer (Cf. 1761, n. 150, P.317), o enfraquecimento da força vital era a causa das fraquezas do ânimo, que eventualmente poderiam causar a impotência (Ohnmacht) ou a paralisia (Lähmungen) de um órgão do corpo humano. Contrariamente às fraquezas do ânimo, as doenças da bílis escuras são disfunções da cabeça, desde que alterações corpóreas produzam modificações cerebrais, que ocasionem os transtornos do ânimo. As deficiências da cabeça são efeitos de causas corpóreas que, de um lado são as manifestações de um cérebro perturbado e, de outro lado, são manifestações do desfalecimento de algum dos órgãos do corpo humano. Segundo Kant, a impotência (Ohnmacht) acomete a memória, o entendimento e a sensação, por isto tal distúrbio deve ser entendido como uma falta de força, um desfalecimento, que em tese somente poderia ser curado com o insuflar de uma nova vida no sentido ou na faculdade afetada. Tanto as fraquezas do ânimo quanto as doenças podem ser organizadas no Ensaio sobre as doenças da cabeça na seguinte tabela:

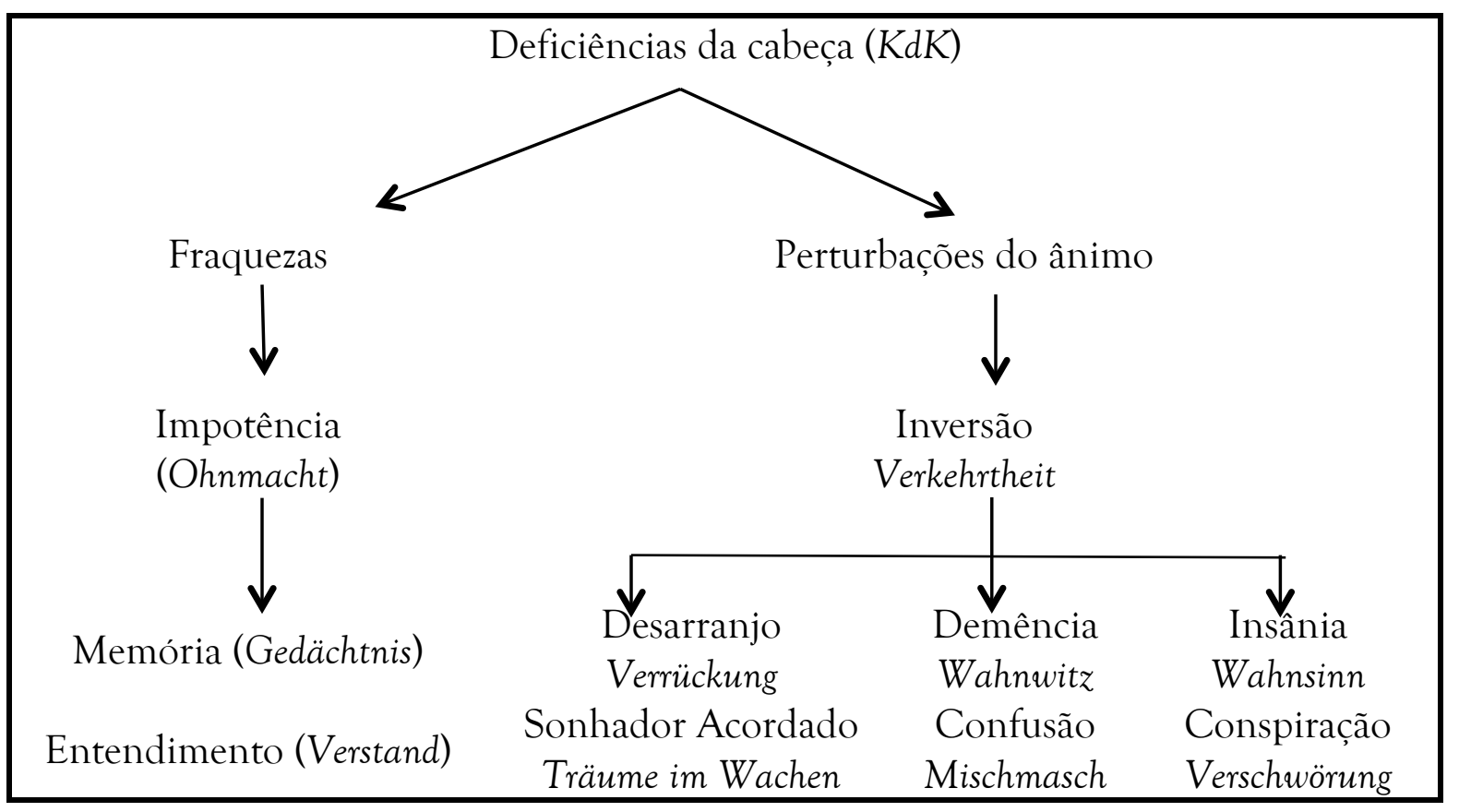




\begin{tabular}{|cccc|}
\hline & Entendimento & Razão & Entendimento \\
Sensação (Empfindung) & Vaculdade de jul- \\
& Verstand/Empfindung & Vernunft & $\begin{array}{c}\text { gar/Verstand } \\
\text { gar }\end{array}$ \\
\hline
\end{tabular}

Embora Kant tenha separado as deficiências da cabeça em dois tipos, elas são problemas corpóreos, por um lado, as fraquezas remetem ao enfraquecimento da força vital, que causa a impotência e, por outro lado, as perturbações do ânimo são um tipo de inversão (Verkehrtheit), que transforma a sensação corporal em interna (psicológica). Não há como explicar o mecanismo da inversão sem associá-lo com os três tipos de doenças da cabeça citadas por Kant. Os três tipos de enfermidade do ânimo são: o desarranjo (Verrückung), a insânia (Wahnsinn) e a demência (Wahnwitz) $(K d K 2: 264)^{12}$.

\section{De acordo com Kant, o desarranjo é}

[...] a condição da pessoa perturbada segundo a qual está habituada a representar, no estado de vigília, sem um grau de doença particularmente acentuado certas coisas ausentes, como sendo claramente sentidas. Quem sofre de desarranjo é alguém que sonha acordado $(K d K$ $2: 265)^{13}$.

O enfermo que sofre de desarranjo não consegue dis-

\footnotetext{
${ }^{12}$ Conforme o Dicionário dos Irmãos Grimm, o termo Wahnsinn (demência) fora utilizado como mais frequência a partir de 1780 como substantivo do adjetivo wahnisinnig (louco ou alucinado). Este substantivo fora usado para indicar uma falta de sentido (Sinnlosigkeit) ou cegueira (Verblendung) do doente, que ao imaginar projeta um objeto no espaço. Diferentemente do Wahnsinn, o termo Wahnwitz (insânia) é originário do século XVI, neste período histórico ele fora empregado para denotar um tipo de irracionalidade, desrazão ou futilidade. No século XVIII, ele recebeu uma conotação científica que consistia na distinção entre Wahnsinn e Wahnwitz, este significa um grau maior de ilusão em comparação com aquele. Verrückung (desarranjo) fora um termo originário do século XVI, sendo ele utilizado para designar uma perturbação mental. Diferentes daqueles distúrbios mentais, neste o transtorno mental têm causas fisiológicas, tendo nesse período histórico como hipótese o deslocamento do cérebro.

${ }^{13}$ Diese Eigenschaft des Gestörten, nach welcher er ohne einen besonders merklichen Grad einer heftigen Krankheit im wachenden Zustande gewohnt ist, gewisse Dinge als klar empfunden sich vorzustellen, von denen gleichwohl nichts gegenwärtig ist, heißt die Verrückung. Der Verrückte ist also ein Träumer im Wachen.
} 
tinguir as representações sensíveis das representações produzidas por sua alma, que chamá-las-emos de representações oniricas $^{14}$, pois o próprio Kant chamou tal doente de sonhador acordado. A diferença entre as representações sensíveis e as representações oníricas é o grau de força e de vividez de cada uma, dado que a sonial possui força e vividez menor do que a sensível. Em particular no Ensaio sobre as doenças da cabeça, Kant adotou um posicionamento filosóficomédico, já que classificou as doenças da cabeça de acordo com o diagnóstico médico que lhe permitiu tipificar três tipos de erros no processo judicativo, ainda que tal critério fosse empírico. Deste modo, o estado sonial do ser racional finito propiciava um tipo de obscurecimento das impressões sensíveis, que perdiam a sua força e vividez, visto que as representações obscuras também se originavam nas sensações. A inversão que ocorre no desarranjo é a substituição da sensação sensível pela sensação onírica, esta troca ocasiona o erro no processo judicativo. Dito de outro modo, o erro judicativo é a adoção da sensação errada, o doente colocou a sensação onírica no lugar da sensação sensível (Cf. KdK 2:268).

Ao contrário do desarranjo, a insânia (Wahnsinn) é "atentar contra as regras gerais do entendimento mesmo nos juízos mais próximos da experiência” (KdK 2:268) ${ }^{15}$. Rauer (Cf. 2006, P. 138) classificou a insânia como a doença da conspiração (Verschwörung), visto que tal distúrbio projeta as propriedades do eu psicológico como um objeto do mundo externo. $\mathrm{O}$ doente imagina ser vítima de algum tipo

\footnotetext{
${ }^{14}$ Usamos o adjetivo onírico para distinguir as representações no estado de sono das representações do estado de vigília, embora Kant não tenha utilizado tal termo nessa obra.

${ }^{15}$ [...] Krankheit ist der erste Grad der Wahnsinn, welcher in den nächsten Urteilen aus der Erfahrung der gemeinen Verstandesregel entgegen handelt.
} 
de conspiração, ele interpreta o comportamento de outrem como um tipo de ameaça. Kant não foi específico em determinar de que modo ocorre a inversão, mas podemos inferir que ela diz respeito às representações criadas pela faculdade da imaginação poética, que alterariam o sentido das percepções sensíveis. Esse tipo de enfermo acredita ter inimigos em toda parte, uma vez que interpreta os gestos, as palavras de outrem e os acontecimentos do mundo exterior como se fizessem parte de uma teoria da conspiração. O erro no procedimento judicativo é a inversão entre o imaginado e o percebido, pois o imaginado ocupa o lugar do percebido na formulação de um juízo sobre o mundo dos objetos sensíveis.

A insânia é o primeiro grau de contaminação da faculdade do entendimento e o segundo grau é a demência, que sinaliza a desordem da razão. Para Kant, "o segundo grau da perturbação da mente diz respeito à faculdade do conhecimento superior, a razão posta em desordem, na medida em que se perde de um modo disparatado em juízos finamente construídos sobre conceitos gerais, e pode se designada por demência (Wahnwitz)" (KdK 2:268) ${ }^{16}$. Essa enfermidade consiste no funcionamento análogo entre o entendimento e a razão - esta exerce a função daquele. Por exemplo, em um juízo categórico afirmativo o entendimento liga o predicado com o sujeito, uma vez que a exclusão do predicado inviabiliza o sujeito. Na demência a razão exerce a função do entendimento, na medida em que trata dos conceitos universais como se fossem sujeitos extensionais. Para com-

\footnotetext{
${ }^{16}$ Der zweite Grad des in Ansehung der oberen Erkenntniskraft gestörten Kopfes ist eigentlich die in Unordnung gebrachte Vernunft, insofern sie sich in eingebildeten feineren Urteilen über allgemeine Begriffe auf eine ungereimte Art verirrt, und kann der Wahnwitz genannt werden.
} 
preendermos como ocorre a inversão nos juízos universais, nós recorremos aos cursos de Kant ministrados nos invernos de 1765-66, dado que na aula de lógica o autor delimita as fontes e a validade do conhecimento ao especificar como cada faculdade superior opera. Em Nachricht, Kant argumentou que "o ensino do método característico da sabedoria do mundo (Weltweisheit) é a zétesis, como alguns indicaram (de zétesis), isto é, investigante, e a razão já treinada tornam-se apenas em diferentes partes dogmáticas, isto é, decidida" (Nachricht 2:307). O problema na execução do juízo no Ensaio sobre as doenças da cabeça é tal qual no Nachricht, na medida em que Kant distinguiu a função do entendimento e da razão ao delimitar o domínio de operação de cada um. Deste modo, quando a razão opera de forma investigante, ela generaliza a experiência particular, assim tornando-a um tipo de critério, que serve de base para investigar outras experiências particulares. Contudo, a generalização de determinada experiência particular é insuficiente, pois a razão não opera de forma investigante, mas sim decidida. Por fim, a característica essencial da demência é a tendência em misturar (Mischmasch) (Cf. KdK 2:268) peças de quebra-cabeças fúteis e acreditar decifrar profecias, enigmas etc.

Apesar de reconhecer a dificuldade de explicar a origem desses distúrbios do ânimo, Kant sugeriu a hipótese de que possivelmente as causas deles eram mais digestivas do que cerebrais, todavia ele não a desenvolveu. Mas, afirmara que tais eram manifestações do cérebro doente, que, combinadas com as paixões, possibilitaram derivar um conjunto de doenças da alma ${ }^{17}$.

\footnotetext{
${ }^{17}$ Cf. Todas as demais manifestações do cérebro doente podem ser entendidas, no meu parecer, Cont.
} 


\section{SINTOMA E A FACULDADE DA IMAGINAÇÃO REPRODUTIVA}

\section{Diferentemente da obra de 1764, na Antropologia de um pon- to de vista pragmático, publicada em 1798, Kant diferenciou os males da alma em fraquezas do ânimo e em doenças do ânimo. Para uma melhor compreensão da diferença entre a fraqueza e a doença do ânimo, cito-o:}

Os defeitos da faculdade de conhecer são fraquezas (Gemütsschwächen) ou doenças (Gemütskrankheiten) do ânimo. As enfermidades da alma relativas à faculdade de conhecer podem ser inseridas em dois gêneros principais. Um é a atrabílis (hipocondria) e o outro é a perturbação mental (mania). Na primeira, o enfermo é consciente de que o curso de seus pensamentos não vai bem: sua razão não tem poder suficiente sobre si mesma para dirigir, deter ou impulsionar o andamento deles. Alegrias e preocupações fora de hora, portanto, caprichos, alternam nele, como o clima que se tem de aceitar tal qual é. - A segunda é um curso arbitrário de seus pensamentos, que tem sua regra (subjetiva), a qual, porém é contrária às regras (objetivas) que concordam com as leis da experiência (Anth $7: 202)^{18}$.

O critério utilizado por Kant para classificar as enfermidades da cabeça em fraquezas e em doenças do ânimo é

\footnotetext{
quer como graus diferentes dos estados referidos, que como uma infeliz combinação destes males entre si, ou ainda como resultado do enxerto em paixões fortes, de maneira que as podemos subordinar à classificação anterior. Alle übrige Erscheinungen des kranken Gehirns können, wie mich dünkt, entweder als verschiedene Grade der erwähnten Zufälle, oder als eine unglückliche Vereinbarung dieser Übel unter einander, oder endlich als die Einpfropfung derselben auf mächtige Leidenschaften angesehen und den angeführten Classen untergeordnet werden ( $K d K ~ 2: 264)$.

${ }^{18}$ Die Fehler des Erkenntnisvermögens sind entweder Gemütsschwächen, oder Gemütskrankheiten. Die Krankheiten der Seele in Ansehung des Erkenntnisvermögens lassen sich unter zwei Hauptgattungen bringen. Die eine ist die Grillenkrankheit (Hypochondrie) und die andere das gestörte Gemüt (Manie). Bei der ersteren ist sich der Kranke wohl bewusst, daß es mit dem Laufe seiner Gedanken nicht richtig zugehe: indem den Gang derselben zu richten, ihn aufzuhalten oder anzutreiben seine Vernunft nicht hinreichende Gewalt über sich selbst hat. Unzeitige Freude und unzeitige Bekümmernisse, mithin Launen wechseln wie das Wetter, das man nehmen muss, wie es sich findet, in ihm ab. Das zweite ist ein willkürlicher Lauf seiner Gedanken, der seine eigene (subjektive) Regel hat, welche aber den (objektiven) mit Erfahrungsgesetzen zusammenstimmenden zuwider läuft.
} 
o sintoma, que se manifesta nas faculdades cognitivas. As fraquezas do ânimo dizem respeito ao sentido interno, o qual foi definido deste modo: "o sentido interno não é a apercepção pura, uma consciência do que o ser humano faz, pois esta pertence à faculdade de pensar, mas do que ele sofre quando é afetado pelo jogo de seus próprios pensamentos" (Anth 7:161) ${ }^{19}$. O sentido interno delimitado ao modo como o corpo sofre ao ser afetado pelos jogos dos pensamentos não faz parte do conhecimento pragmático, devido a não problematizar o que o homem faz de si, mas sim como o seu corpo sofre ao ser afetado pelos jogos do pensamento. Assim, o sentido interno trata das alterações psicológicas do homem, por isso ele refere-se à unidade de ânimo no sentido material. Ainda conforme Kant,

[...] que a alma é o órgão do sentido interno, do qual se afirma que está sujeito também a ilusões, que consistem em que o ser humano toma os fenômenos desse sentido por fenômenos externos, isto é, ficções por sensações ou as tem até mesmo por inspiração de que outro ser é a causa, ser, porém, que não é objeto do sentido externo: no qual a ilusão é desvario (Schwärmerei) ou também sonho de visionário (Geisterseherei), e ambos, engano do sentido interno (Anth $7: 161)^{20}$.

Segundo a citação, o desvario ou o sonho de visionário são distúrbios do sentido interno, que basicamente consistem na conversão de uma sensação do sentido interno numa sensação do sentido externo, o qual é o modo como o

\footnotetext{
${ }^{19}$ Der innere Sinn ist nicht die reine Apperzeption, ein Bewusstsein dessen, was der Mensch tut, denn dieses gehört zum Denkungsvermögen, sondern was er leidet, wiefern er durch sein eignes Gedankenspiel affiziert wird.

${ }^{20}[\ldots .$.$] die Seele ist das Organ des inneren Sinnes, von dem nun gesagt wird, daß er auch Täus-$ chungen unterworfen ist, die darin bestehen, daß der Mensch die Erscheinungen desselben entweder für äußere Erscheinungen, d. i. Einbildungen für Empfindungen, nimmt, oder aber gar für Eingebungen hält, von denen ein anderes Wesen, welches doch kein Gegenstand äußerer Sinne ist, die Ursache sei: wo die Illusion als dann Schwärmerei oder auch Geisterseherei und beides Betrug des inneren Sinnes ist.
} 
corpo é afetado por um dos seus cincos sentidos. Conforme Rauer (Cf. 2006, P.147), "ainda no Ensaio sobre as doenças da cabeça, Kant apresentou uma simetria entre; por um lado a saúde mental (a razão, a filosofia) e por outro, as doenças da cabeça (como uma perturbação da disposição da razão à inversão)" ${ }^{21}$. Para Rauer, na obra de 1764 , a mente perturbada era definida a partir da saudável, que era afetada por uma disposição natural da razão em dissolver as fronteiras limítrofes entre as duas fontes do conhecimento, que são o entendimento e a sensibilidade. Ao contrário do Ensaio sobre as doenças da cabeça, na Antropologia de um ponto de vista pragmático Kant caracterizou as doenças da cabeça através do sintoma, que é observado a partir do funcionamento das faculdades cognitivas. Na obra de 1798, as fraquezas do ânimo e as doenças do ânimo podem ser agrupadas do seguinte modo:

\begin{tabular}{|c|c|c|}
\hline \multicolumn{3}{|c|}{ Doenças de ânimo (Gemütskrankheiten) } \\
\hline \multirow{2}{*}{$\begin{array}{c}\text { Representação sensível } \\
\text { (Sinnenvorstellung) }\end{array}$} & $\begin{array}{c}\text { Amência (amentia) } \\
\text { (Unsinnigkeit) }\end{array}$ & Tumultuosa (tumultuarische) \\
\cline { 2 - 3 } & $\begin{array}{c}\text { Demência (dementia) } \\
\text { (Wahnsinn) }\end{array}$ & Metódica (methodische) \\
\hline $\begin{array}{c}\text { Faculdade de Julgar } \\
\text { (Urteilskraft) }\end{array}$ & $\begin{array}{c}\text { Insânia (insânia) } \\
\text { (Wahnwitz) }\end{array}$ & Metódica fragmentária \\
\hline $\begin{array}{c}\text { Razão } \\
\text { (Vernunft) }\end{array}$ & $\begin{array}{c}\text { Vesânia (vesania) } \\
\text { (Aberwitz) }\end{array}$ & Sistemática (systematische) \\
\hline
\end{tabular}

Fraquezas de ânimo (Gemütsschwächen)

\begin{tabular}{|l|c|c|c|}
\hline Órgão interno afetado & Faculdade afetada & Doença & Características \\
\hline
\end{tabular}

\footnotetext{
${ }^{21}$ Noch in dem Versuch über die Krankheiten des Kopfes ging Kant von einer Symmetrie zwischen dem gesunden Kopf (der Vernunft, der Philosophie) einerseits und dem kranken Kopf (als einer Störung der Vernunftanlagen durch die Verkehrtheit) andererseits aus.
} 


\begin{tabular}{|c|c|c|c|}
\hline \multirow{2}{*}{$\begin{array}{l}\text { Sensações corporais } \\
\text { do sentido interno } \\
\text { (körperliche Empfindung) }\end{array}$} & \multirow{2}{*}{$\begin{array}{l}\text { Faculdade da imagi- } \\
\text { nação reprodutiva } \\
\text { (reproduktive Einbil- } \\
\text { dungskraft) }\end{array}$} & $\begin{array}{c}\text { Hipocondria } \\
\text { (Hypochondrie) } \\
\text { (Grillenkrankheit) }\end{array}$ & $\begin{array}{l}\text { Sonhador } \\
\text { acordado } \\
\text { Fantasista } \\
\text { Entusiasta }\end{array}$ \\
\hline & & $\begin{array}{c}\text { Melancolia } \\
\text { (Melancholia) } \\
\text { (Tiefsinnigkeit) }\end{array}$ & $\begin{array}{c}\text { Inclinação } \\
\text { para o } \\
\text { sofrimento } \\
\text { (Zum Grämen } \\
\text { geneigte) }\end{array}$ \\
\hline
\end{tabular}

Ao comparamos os sintomas e as causas das fraquezas de ânimo descritas na Antropologia de um ponto de vista pragmático e no Ensaio sobre as doenças da cabeça, a diferença entre as obras pode ser exemplificada no detalhamento da faculdade da imaginação reprodutiva. Na obra de 1798, Kant destaca a função da faculdade da imaginação reprodutiva, visto que "uma das fraquezas da mente é estar atada pela imaginação reprodutiva a uma representação a que se aplica grande atenção, ou uma atenção detida, e dela não poder se afastar, isto é, não poder tornar novamente livre o curso da imaginação” (Anth 7:206) 22. Na obra de 1764, não há uma diferenciação da função da faculdade da imaginação em reprodutiva e em produtiva, nela essa capacidade fora chamada de faculdade poética criadora (schöpferische Dichtungsfähigkeit) (Cf. KdK 2:264). Ela teria a capacidade de suscitar sensações fortes equivalentes às originadas de objetos existentes no mundo sensível. Em conformidade com Kant, a faculdade poética criadora opera de duas formas: pintando imagens de coisas ausentes na sensibilidade ou completando-as por meio de semelhanças imperfeitas, que diz respeito à associação de representações (Cf. $K d K$

\footnotetext{
${ }^{22}$ Es ist eine von den Gemütsschwächen, durch die reproduktive Einbildungskraft an eine Vorstellung, auf welche man große oder anhaltende Aufmerksamkeit verwandt hat, geheftet zu sein und von ihr nicht abkommen, d. i. den Lauf der Einbildungskraft wiederum frei machen zu können.
} 
2:264) ${ }^{23}$. Deste modo, o homem torna-se incapaz de poder ser consciente das sensações do sentido externo porque as sensações produzidas pela faculdade poética criadora ocupam o lugar das impressões originadas a partir da presença dos objetos externos.

Em 1798, Kant distinguiu as funções da faculdade da imaginação nos presentes termos: "ou é produtiva, isto é, uma faculdade de exposição original do objeto (exhibitio originaria), que antecede a experiência, ou reprodutiva, uma faculdade de exposição derivada (exhibitio derivativa), que traz de volta ao espirito uma intuição empírica que já se possuía anteriormente" (Anth 7:168). Poderíamos relacionar a função reprodutiva da faculdade da imaginação com a faculdade poética criadora, visto esta suscitar representações já experimentadas na ausência de um objeto na sensibilidade e exercer a função associativa. Todavia, haveria uma terceira faculdade da imaginação na Antropologia de um ponto de vista pragmático - a faculdade da imaginação sensível (sinnlichen Dichtungsvermögens) - dividida em três espécies distintas, a saber, a imaginatio plastica, a imaginatio associans e a imaginatio affinitas (Cf. Anth 7:174). Mas, nós a compreendemos como uma derivação da função reprodutiva da faculdade da imaginação, logo não vamos desenvolvê-las neste trabalho. Ao contrário do Ensaio sobre as doenças da cabeça, na Antropologia de um ponto de vista pragmático houve o desenvolvimento detalhado da faculdade da imaginação - este é um dos pontos de divergência entre essas obras.

\footnotetext{
${ }^{23}$ Die Seele eines jeden Menschen ist selbst in dem gesundesten Zustande geschäftig, allerlei Bilder von Dingen, die nicht gegenwärtig sind, zu malen, oder auch an der Vorstellung gegenwärtiger Dinge einige unvollkommene Ähnlichkeit zu vollenden durch einen oder andern chimärischen Zug, den die schöpferische Dichtungsfähigkeit mit in die Empfindung einzeichnet.
} 


\section{A TEORIA DA LOUCURA EM KANT: A} $\begin{array}{lllr}\text { DIFERENÇA ENTRE } & \text { A } & \text { RECEPTIVIDADE } \\ \text { (EMPFÄNGLICHKEIT), } & \text { A } & \text { SENSITIVIDADE } \\ \text { (EMPFINDSAMKEIT) } & \text { E } & \text { A } & \text { SUSCETIBILIDADE } \\ \text { (EMPFINDELEI) } & & & \end{array}$

Ao continuarmos a comparação entre o Ensaio sobre as doenças da cabeça e a Antropologia de um ponto de vista pragmático, há uma diferença fundamental na estrutura dos textos. Essa diferença diz respeito à articulação do sentido interno e do externo, que na obra de 1764 não está desenvolvido tal como encontramos na obra de 1798 . Ao sustentar a alteração estrutural entre as obras, procuramos salientar como tal diferença influenciou na determinação do modo causal das doenças do ânimo. Em Ensaio sobre as doenças da cabeça, Kant (Cf. Anth 2:264) defendeu que as doenças da cabeça eram manifestações do cérebro doente, e que as paixões potencializavam essas doenças. Em Antropologia de um ponto de vista pragmático, o autor problematizou as doenças da cabeça a partir do sentido interno e externo (Cf. Anth 7:153\202), sob a perspectiva de uma dupla implicação entre os processos fisiológicos e os processos mentais.

Para compreendemos a diferença entre as obras supracitadas, torna-se necessário consultarmos a reflexão 1503, a qual se encontra no volume 15 da Akademie Ausgabe. Cito o trecho:

Sentido externo: 1. Sensação vital (g vagus; sentimento, prazer e desprazer) por onde apenas sentimos os afetos da nossa vida. 2. Sensação do órgão ( $g$ fixus), por onde um objeto se apresenta. Em todos os nervos desse órgão. Pertence a cada calor (s percorre $\backslash$ ), frio. Por 
meio do pensamento suscita: terror e calafrio ${ }^{24}$ (Colleg 15:802).

De acordo com a proposta de organização histórica de Adickes, o trecho catalogado como Reflexão 1503 ( $\psi 1-2$. L Bl. Ha 20), no qual Kant problematizou a maneira como o corpo afeta o ânimo externamente e, como o ânimo afeta o corpo internamente; foi escrito possivelmente entre 1780 e 1783 e, com possíveis modificações entre 1783 e 1784. Especialmente na Reflexão 1503, o autor articula o sentido interno como um tipo de sensação vital (Vitalempfindung), que permite ao ânimo afetar o corpo, contanto que separemos dois tipos de sensações produzidas por representações ocasionadas pelo sentido interno. Antes de definirmos os dois tipos, citaremos um trecho da Antropologia de um ponto de vista pragmático, no qual Kant argumentou que:

a sensação de calor e frio, mesmo aquela que é suscitada pela mente (por exemplo, pela esperança ou temor que aumentam rapidamente), pertence ao sentido vital. $\mathrm{O}$ calafrio que percorre o próprio ser humano à representação do sublime, e o terror com que já tarde da noite histórias da corochinha fazem as crianças fugirem para a cama, são dessa última espécie; eles penetram o corpo, onde nele haja vida (Anth 7:154) $)^{25}$.

Isso significa que o sentido interno, tido como a sensação que percorre um corpo vivo, pode ser compreendido de dois modos: o primeiro trata das sensações de prazer e de desprazer, do sentimento de sublime e de terror; o segundo

\footnotetext{
24 Äußerer Sinn: 1. Vitalempfindung (g vagus; Gefühl, Vergnügen und Schmerzt), wodurch wir nur unser Leben affichiert fühlen, 2. Organempfindung (g fixus), wodurch wir ein Objekt vorstellen. In jener alle Nerven, in diesem ein Organ. Zu jener gehört Wärme (s brennend), Kälte. Durch Gedanken erregt: Gräuseln und Schauer.

${ }^{25}$ Die Empfindung der Wärme und Kälte, selbst die, welche durchs Gemüt erregt wird (z. B. durch schnell waschsende Hoffnung oder Furcht), gehört zum Vitalsinn. Der Schauer, der den Menschen selbst bei der Vorstellung des Erhabenen überläuft, und das Gräuseln, womit Ammenmärchen in später Abendzeit die Kinder zu Bette jagen, sind von der letzteren Art; sie durchdringen dem Körper, so weit als in ihm Leben ist.
} 
diz respeito aos sentimentos mórbidos, que são afetações da mente sobre o corpo. Torna-se importante observar que, ao identificarmos cada tipo de sensação corpórea causada pelo ânimo, não temos a intenção de estratificá-lo em diferentes entidades, que poderiam sugerir a estratificação do sujeito transcendental, ou seja, em um sujeito empírico e em um sujeito transcendental. Pelo contrário, procuramos salientar os diferentes tipos de sensações corporais causadas por atividades anímicas. Loparic (Cf. 2009, P.24) argumentou que investigar a relação entre a razão e a sensibilidade consiste em dizer que a filosofia transcendental de Kant é uma semântica a priori, a qual resulta, em parte, em uma teoria das representações a priori que trata dos conceitos e dos juízos e, em outra parte, em uma teoria da interpretação e da aplicabilidade das representações em diferentes domínios de dados fornecidos pela sensibilidade humana. Conforme Loparic, "no caso das ideias teóricas, o domínio de interpretação é o constituído de dados intuitivos; no caso das práticas, é o de sentimentos morais; no caso de ideias estéticas e teleológicas, outros domínios sensíveis devidamente explicitados" (LOPARIC 2009, P.24). Ainda de acordo com Loparic, mais especificamente no que diz respeito ao sentido interno, esse autor argumentou que:

a existência de um sentimento de respeito implica a disposição (Anlage) do ânimo (Gemüt) para receber (empfangen) tal sentimento. Essa receptividade (Empfänglichkeit) para o respeito pela lei é, ela mesma, chamada por Kant de "sentimento moral" (das moralische Gefühl, 1794, P. 16). Esse sentimento deve ser distinguido da receptividade para as sensações (nossos estados subjetivos que podem se tornar partes de representações cognitivas) e que é chamada de "sentido" (Sinn), externo ou interno (cf. 1797, P. 2n). Desde a segunda Crítica, Kant afirma, portanto, a existência de dois diferentes tipos de (Sinnlichkeit), uma cognitiva - afetada pelos objetos eles mesmos -, e uma não cognitiva, afetada não pelos objetos, mas pelas representações de 
objetos (1797, P. 2). Quando os efeitos recebidos provêm de ideias práticas, a sensibilidade é chamada de volitiva moral. Finalmente, quando a determinação do ânimo resulta de ideias morais, a sensibilidade em jogo é, ela mesma, chamada de moral (LOPARIC 2009. P. 37).

Ao defendermos dois tipos de sensações causadas pelo ânimo, as quais Kant incluiu no sentido interno, na Antropologia de um ponto de vista pragmático, almejamos dar ênfase que: o primeiro tipo de acepção cognitiva-teórica diz respeito ao modo como os objetos sensíveis afetam a sensibilidade; o segundo tipo de acepção cognitiva não é teórica, dado tratar das sensações que não são causadas pela afetação dos objetos na sensibilidade, mas sim pela representação desses objetos provocada pelo ânimo. A sensação provocada por representação de um objeto consiste em impressões sensíveis ocasionadas pelo sentido interno, que, segundo Kant, é o modo de como o ânimo afeta a sensibilidade. Deste modo, ao falarmos em dois tipos de sensações do sentido interno na Antropologia de um ponto de vista pragmático, objetivamos salientar que há sensações ocasionadas por representações de objetos que se referem ao aspecto material do ânimo, e há sensações ocasionadas por atividades cognitivas, as quais pertencem ao ânimo. É importante ressaltar que concordamos com a tese de Loparic de que o domínio de aplicabilidade dos juízos é constituído por dados intuitivos, que no caso prático é o sentimento de respeito à lei, e que tais sensações cognitivas, do primeiro tipo, são determinadas por um domínio específico de aplicabilidade. As sensações do segundo modo pertencem ao domínio da psicologia empírica, na medida em que são sensações causadas por representações de objetos na sensibilidade. Tais sensações são caracterizadas como doenças da cabeça, devido ao 
poder mórbido que o ânimo exerce sobre o corpo.

Ainda de acordo com os dois tipos de sensações produzidas por atividades do sentido interno, na Antropologia de um ponto de vista pragmático, Kant argumentou que:

A sensitividade (Empfindsamkeit) não é contrária àquela equanimidade, pois é uma faculdade e uma força de aceitar tanto o estado de prazer quanto de desprazer, ou como de impedir o ânimo e também uma escolha. Em compensação, a suscetibilidade (Empfindelei) é uma fraqueza, de se deixar afetar mesmo contra a vontade, porque se compartilha o estado de espírito dos outros, os quais podem, por assim dizer, jogar ao bel-prazer com o órgão do indivíduo suscetível (Anth 7:236) $)^{26}$.

No trecho acima citado, o autor diferenciou a sensitividade (Empfindsamkeit) da suscetibilidade (Empfindelei), porquanto ambas dizem respeito à capacidade de ânimo em impedir ou fomentar estados de prazer e desprazer. A sensitividade (Empfindsamkeit) diz respeito à capacidade do agente moral de ter delicadeza (Zartheit) para com o sentimento de outrem, visto que tal é condição de generosidade (Großmut). Para Kant, "equânime é aquele que nem se rejubila nem se entristece, e difere bastante daquele que é indiferente diante dos acasos da vida, isto é, do sentimento embotado" (Anth 7:235) ${ }^{27}$. Por isso é que a sensitividade pressupõe uma delicadeza e generosidade do agente, pois sem tais características ele não pode ser solidário com outrem. Segundo Kant, "ela é máscula, pois o homem que quer poupar pesares ou dor a uma mulher ou a uma criança

\footnotetext{
${ }^{26}$ Empfindsamkeit ist jener Gleichmütigkeit nicht entgegen. Denn sie ist ein Vermögen und eine Stärke, den Zustand sowohl der Lust als Unlust zuzulassen, oder auch vom Gemüt abzuhalten, und hat also eine Wahl. Dagegen ist Empfindelei eine Schwäche, durch Teilnehmung an anderer ihrem Zustande, die gleichsam auf dem Organ des Empfindelnden nach Belieben spielen können, sich auch wider Willen affizieren zu lassen.

${ }^{27}$ Gleichmütig ist der, welcher sich weder erfreut noch betrübt, und von dem, der gegen die Zufälle des Lebens gleichgültig, mithin von stumpfem Gefühl ist, sehr unterschieden.
} 
precisa ter de participar do sentimento destas tanto quanto é necessário para julgar o sentimento dos outros, não por sua força, mas pela fraqueza deles, e a delicadeza do seu sentimento é necessária à generosidade" (Anth 7:236). Assim, o agente moral, particularmente neste caso masculino, deve possuir uma delicadeza com os sentimentos das crianças e das mulheres, senão ele não será generoso com estes, e o agente moral masculino terá uma participação inativa aos sentimentos de outrem.

A comoção ao sentimento, por exemplo, da criança e da mulher pelo homem, não ocorre devido à fraqueza de ânimo dele para com aqueles. Ao contrário, é o exercício da força do ânimo em aceitar ou rejeitar o estado de prazer e desprazer, pois eles são resultados do exercício da escolha do homem como ser racional. Diferente da sensitividade (Empfindsamkeit), Kant destacou a suscetibilidade (Empfindelei), a qual trata do modo como o corpo é afetado pelo ânimo, uma vez que o ânimo pode ser contaminado por sentimentos mórbidos de outras pessoas e causar sensações no corpo. Kant definiu a suscetibilidade do ânimo como um tipo de fraqueza, a qual diz respeito à capacidade do ânimo em causar representações no corpo. Esse tipo de sensação produzida pelo ânimo faz parte da psicologia e não da antropologia, pois como o próprio Kant escreveu: "o sentido interno não é a apercepção pura, uma consciência do que o ser humano faz, pois esta pertence à faculdade de pensar, mas do que ele sofre quando é afetado pelo jogo de seus próprios pensamentos" (Anth 7:161) ${ }^{28}$. Deste modo, ao

\footnotetext{
${ }^{28}$ Der innere Sinn ist nicht die reine Apperzeption, ein Bewusstsein dessen, was der Mensch tut, denn dieses gehört zum Denkungsvermögen, sondern was er leidet, wiefern er durch sein eignes Gedankenspiel affiziert wird.
} 
falarmos de tipos de sensações ocasionadas pelo ânimo temos que distinguir: I) a suscetibilidade (Empfindelei) da sensibilidade, que, devido à fraqueza do ânimo, permite que o corpo seja afetado por representações de objetos ou de doenças; II) a sensitividade (Empfindsamkeit) da sensibilidade, que permite ao agente racional não ser indiferente ao sofrimento de outrem, que não ocorre pela fraqueza do ânimo, ao contrário, ocorre pela sua força; III) a receptividade (Empfänglichkeit) do sentimento moral, que é o prazer ou desprazer que surge a partir da representação da lei moral.

Para esclarecer a diferença entre a receptividade (Empfänglichkeit) da sensitividade (Empfindsamkeit) e da suscetibilidade (Empfindelei), cito um trecho da Metafísica dos Costumes (MS 6:400):

Não é apropriado chamar a este sentimento [sentimento moral] de sentido moral; pois por termo "sentido" entende-se geralmente uma faculdade teórica perceptiva referida a um objeto: ao invés, o sentimento moral (como prazer ou desprazer em geral) é algo meramente subjetivo, que nem completamente destituído de sentimento moral; porque, no caso de absoluta falta de receptividade para esta situação, ele estaria morto, e se a força moral vital (para falar na linguagem dos médicos) já não pudesse estimular este sentimento, a humanidade dissolver-se-ia na mera animalidade (como se seguisse leis da química) e fundir-se-ia irremediavelmente na massa dos outros seres naturais ${ }^{29}$.

Ao alinharmos a Metafísica dos Costumes e a Antropologia

\footnotetext{
${ }^{29}$ Dieses Gefühl einen moralischen Sinn zu nennen ist nicht schicklich; denn unter dem Wort Sinn wird gemeiniglich ein theoretisches, auf einen Gegenstand bezogenes Wahrnehmungsvermögen verstanden: dahingegen das moralische Gefühl (wie Lust und Unlust überhaupt) etwas blos Subjektives ist, was kein Erkenntnis abgiebt. - Ohne alles moralische Gefühl ist kein Mensch; denn bei völliger Unempfänglichkeit für diese Empfindung wäre er sittlich todt, und wenn (um in der Sprache der Ärzte zu reden) die sittliche Lebenskraft keinen Reiz mehr auf dieses Gefühl bewirken könnte, so würde sich die Menschheit (gleichsam nach chemischen Gesetzen) in die bloße Thierheit auflösen und mit der Masse anderer Naturwesen unwiederbringlich vermischt werden.
} 
de um ponto de vista pragmático, podemos asseverar que o sentimento moral pertence à sensação vital (Vitalempfindung). Uma vez que, primeiro, a receptividade do sentimento de respeito à lei caracteriza o ser humano como um ser animado e o distingue dos outros animais, visto que ele é um ser racional. Segundo, o sentimento de respeito à lei não é igual ao sentido interno, em sentido cognitivo, porque não é causado pelo modo como o objeto aparece ao ser racional finito e, também em sentido não cognitivo, ou seja, psicológico, que é o efeito de uma representação na sensibilidade. Portanto, parafraseando Kant, o sentimento de respeito à lei é a receptividade do livre arbítrio em ser movida pela razão pura prática. Por conseguinte, a receptividade do sentimento moral, não pode ser confundida nem com a sensitividade (Empfindsamkeit) nem com a suscetibilidade (Empfindelei), pois ambas tratam do modo como o corpo é afetado por representações criadas pelo ânimo.

Referente à diferença entre a sensitividade (Empfindsamkeit) e a suscetibilidade (Empfindelei), Borges (2012, p.118-119) escreveu que:

Minha tese, portanto, é que há uma visão mais sofisticada que é mostrada na Doutrina das Virtudes (1797) e Antropologia (1798), nas quais podemos ver uma distinção entre o que se poderia chamar uma simpatia sensível e uma prática. O primeiro tipo de simpatia seria relacionado com a sentimentalidade (Empfindsamkeit) e significa a capacidade passiva de ser sensível à alegria e dor de outrem. Por ser um sentimento passivo, deve ser denominado de afeto. A simpatia prática, por sua vez, envolve escolha e pode ser treinada para uma resposta correta moralmente nas diversas situações. A possibilidade de cultivo desta simpatia não implica a possibilidade de cultivo de todos os afetos em geral e muito menos a ideia de que não somos passivos em relação as nossas emoções. Logo, a possibilidade de uma mudança radical entre um Kant formal e outro que faz o elogio da responsabilidade pelas nossas emoções deve ser descartada. 
Ao aceitarmos os argumentos apresentados por Borges, primeiro, tanto a sensitividade (Empfindsamkeit) e quanto a suscetibilidade (Empfindelei) tratam da simpatia ao sentimento de outrem. A diferença entre elas é que, a primeira diz respeito à simpatia prática, na qual o agente moral participa do sentimento de outro ser humano, não por fraqueza do seu ânimo, ao contrário, por delicadeza de sentimento, que lhe permite ser generoso com outra pessoa. A segunda refere-se à capacidade do ânimo em ser contaminado por sentimentos mórbidos de outrem, pois é um tipo de fraqueza do ânimo. A fraqueza (Schwäche) do ânimo distingue-se da força (Stärke), uma vez que não é a faculdade de acolher e afastar os pensamentos mórbidos, que permite a generosidade (Großmut) com uma mulher ou uma criança. A fraqueza também não é a participação inativa ao sentimento, para que este seja uma ressonância simpática ao sentimento dos outros e, assim seja afetado apenas de maneira passiva, ou seja, um tipo de indiferença ao sentimento das outras pessoas. A fraqueza denota um tipo de passividade, pois ela pressupõe a capacidade do ânimo ser afetado por representações, contudo é fraqueza na medida em que o ânimo não consegue afastar os sentimentos mórbidos, os quais afetam o corpo. Por isso é que a capacidade do corpo ser afetado por pensamentos mórbidos pertence à suscetibilidade, pois ela é um tipo de fraqueza do ânimo, que lhe permite afetar o corpo a partir de representações de doenças e sentimentos.

\section{CONCLUSÃO}

Retomando a diferença entre as obras supracitadas, no Ensaio sobre as doenças da cabeça as disfunções mentais eram 
causadas por distúrbios corporais, porque era um movimento de um dos órgãos do corpo humano que tornava uma sensação externa em interna. A sensação externa é o modo como o corpo é afetado por coisas corpóreas, que ocorre por meio dos cinco sentidos. Ao contrário da obra de 1764, na Antropologia de um ponto de vista pragmático as doenças da cabeça ocorrem de dois modos, que são: I) a vibração do nervo que torna uma sensação externa em interna, devido à força e à intensidade do movimento e; (II) a suscetibilidade do ânimo por meio de representações de sentimentos mórbidos, os quais afetam o corpo ao causarem sensações. Como se pode constatar, houve a ampliação do modo como as doenças da cabeça afetam o corpo na Antropologia de um ponto de vista pragmático, e esta mudança estrutural do texto é o resultado da relação de dupla implicação entre os estados do ânimo e os estados corporais.

A constatação da ampliação do modo causal das doenças da cabeça na Antropologia de um ponto de vista pragmático em comparação com o Ensaio sobre as doenças da cabeça permite elencar os elementos materiais da natureza humana que tornam possível a exequibilidade de proposições. Esta constatação primeiramente ocorre de forma negativa, na medida em que a onomástica das doenças da cabeça autoriza elaborar a classificação de operações judicativas defeituosas. A classificação das doenças da cabeça a partir das faculdades cognitivas autoriza inferir a ideia de um corpo que é afetado por reações químicas - os sentidos de segunda classe (Cf. Anth 7:154) - e por ações do ânimo. De acordo com as indicações kantianas na introdução da Antropologia de um ponto de vista pragmático, a maneira como o corpo é afetado por operações químicas faz parte da an- 
tropologia fisiológica, visto que trata do que a natureza faz do homem. Contudo, as ações do ânimo sobre o corpo não trata do que a natureza faz do homem, mas sim da maneira como o corpo sofre quando é afetado pelo ânimo.

A maneira de como o ânimo afeta o corpo não faz parte da antropologia empírica, pois este discurso antropológico tematiza o que a natureza faz do homem. Problematizamos tal tema a partir da relação entre as faculdades cognitivas e a ideia de natureza humana. Há dois modos de reconstruir o problema da ideia de uma natureza humana em Kant, a saber: a partir da psicologia transcendental defendida por Kitcher (Cf. 1990) ou a partir da escola semântica defendida por Loparic (Cf. 2005) e Perez (Cf.2013a \b 2009). Kitcher (cf. 1990) defende que a lógica transcendental descreve de que modo e como são possíveis os diferentes processos cognitivos. De acordo com essa intepretação, reconstruir a ideia de natureza em Kant implica em determinar as condições de possibilidade das faculdades cognitivas, ou seja, ela seria reconstruída a partir de uma epistemologia, que determinaria a gêneses dessas faculdades. Loparic (Cf. 2005) sustenta a argumentação de que a lógica transcendental explicita as condições de possibilidade de um discurso válido, essas condições dizem respeito às regras de execução e não às possibilidades das faculdades cognitivas. Por conseguinte, há dois modos de descrever a natureza humana a partir das faculdades cognitivas: i) através da reconstrução genética das faculdades cognitivas, que objetiva determinar o que e quais são as condições que permitem ao homem conhecer; ii) descrever a natureza humana como executora de operações judicativas de diferentes tipos. O primeiro tipo de descrição associa-se a psicologia transcendental na medida em que procura descrever como os processos cognitivos são 
possíveis. $\mathrm{O}$ segundo associa-se a escola semântica na medida em que descreve o homem como executor de regras, que são semânticas e não se interroga pelas condições de possibilidade das faculdades cognitivas.

Neste artigo procuramos evidenciar a ideia da construção de uma natureza humana a partir das faculdades cognitivas, para isto a problematizamos a partir das doenças da cabeça e por meio da capacidade do ânimo em afetar o corpo. Dito de outro modo, neste trabalho, procuramos apresentar o problema da construção da ideia de uma natureza humana em Kant por intermédio das faculdades cognitivas. A metodologia empregada na pesquisa nos permitiu evidenciar os elementos de uma natureza humana, que pode ser reconstruída a partir da psicologia transcendental e da leitura semântica. Todavia, aqui nos limitamos apenas em evidenciar a validade do problema, que em pesquisas futuras pretendemos solucionar.

Abstract: This paper aims to reconstruct the idea of a human nature in Kant through the operation of the cognitive faculties. To accomplish this task, we will problematize the sensitivity from the point of view of head's diseases, which allow us to understand the functioning of human nature from the cognitive faculties. Investigating human nature, through cognitive faculties, means that we will interrogate it about the prospect of what are the material conditions that make possible the feasibility of a priori synthetic propositions. The advantages of this approach are: I) allows understanding how the material substrate changes the judgmental operations and how these delimit it; ii) authorizes to classify different levels of sensitivity operations.

Keywords: diseases of head; mind; receptivity; sensitivity and susceptibility.

\section{REFERÊNCIAS}

KANT, Immanuel: Gesammelte Schriften Hrsg.: Bd. 1-22 Preussische Akademie der Wissenschaften, Bd. 23 Deutsche Akademie der Wissenschaften zu Berlin, ab Bd. 24 
Akademie der Wissenschaften zu Göttingen. Berlin $1900 \mathrm{ff}$. AA Akademie-Ausgabe

Anth Anthropologie in pragmatischer Hinsicht (AA 07)

KdK Versuch über die Krankheiten des Kopfes (AA 02)

Nachricht Nachricht von der Einrichtung seiner Vorlesungen in dem Winterhalbenjahre von 17651766 (AA 02)

BDG Der einzig mögliche Beweisgrund zu einer Demonstration des Daseins Gottes (AA 02)

Refl Reflexion (AA 14-19)

Colleg Collegentwürge aus den 70 er Jahren (AA 15)

KrK Kritik reinen Vernunft

MS Die Metaphysik der Sitten (AA 06)

BORGES, M. L. Razão e emoção em Kant. Pelotas: Editora e Gráfica Universitária, 2012.

CONCEIÇÃO, J. V. C. Onomástica da perturbação de ânimo de acordo com Kant. Páginas de Filosofia (São Bernardo do Campo), v. 4, p. 71-90, 2012.

- Anthopologie Transscendentalis: uma reorientação da teoria dos juizos em Kant. Kant e-Prints. Campinas, Série 2, v. 8, n. 2, p.131-149 jul.-dez., 2013.

FRIERSON, P. Kant on mental disorder. Part 1: an overview. Hist Psychiatry. 2009 Sep;20(79 Pt 3):267-89. PubMed PMID: 20030160. (a)

FRIERSON, P. Kant on mental disorder. Part 2: philosophical 
implications of Kant's account. Hist Psychiatry. 2009 Sep;20 (79 Pt 3):290-310. PubMed PMID: 20030161. (b)

KITCHER, P. Kant's transcendental psychology. New York: Oxford University Press, 1990.

LOPARIC, Z. A Semântica transcendental de Kant. $3^{\circ}$ Ed. Campinas: UNICAMP, Centro de Lógica, Epistemologia e História da Ciência, 2005.

- O fato da razão: uma interpretação semântica. Analytica. vol 4, n.1,1999.

PEREZ, D. O. A relação entre a teoria do juizo e natureza humana em Kant. Educação e Filosofia. Uberlândia, v. 27, n. especial, p. 233-258, 2013a.

- A antropologia pragmática como parte da razão prática em sentido kantiano. Manuscrito - Rev. Int. Fil., Campinas, v. 32, n. 2, p. 357-397, jul.-dez. 2009.

- A relação entre a teoria do juízo e natureza humana em Kant. Educação e Filosofia. Uberlândia, v. 27, n. especial, p. 233-258, 2013b.

RAUER, C. Wahn und Wahrheit: Kants Auseinandersetzung mit dem Irrationalen. Berlin: Akademie Verlag $\mathrm{GmbH}$, 2007.

TERUEL, P. J. Die äußere Schaale der Natur Eine Fußnote zum Versuch über die Krankheiten des Kopfes (1764). KantStudien. v. 104, Issue 1,2013.

Deutsches Wörterbuch von Jacob Grimm und Willhelm Grimm. http://woerterbuchnetz.de/ acessado em 25 jun. 13. 